\title{
Relying on known or exploring for new? Movement patterns and reproductive resource use in a tadpole-transporting frog
}

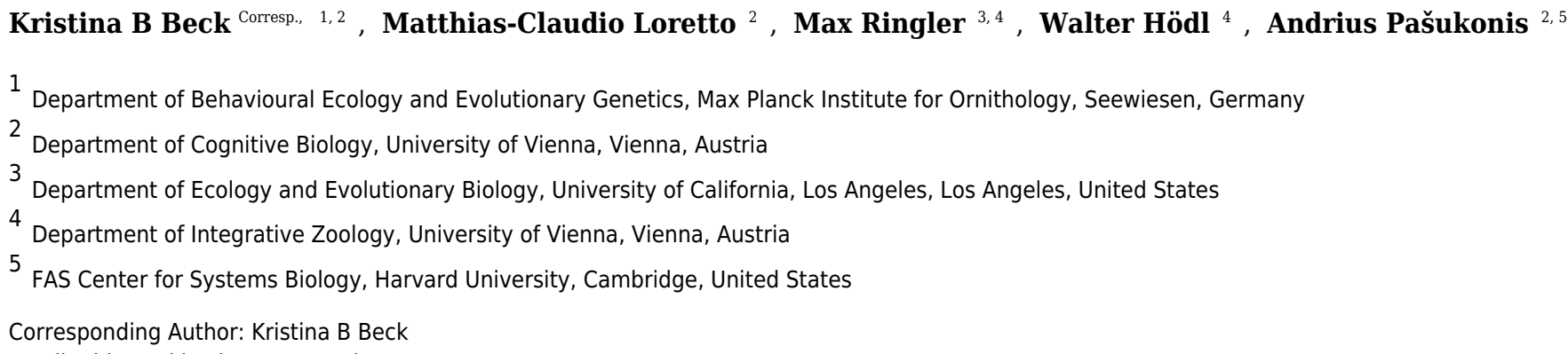

Animals relying on uncertain, ephemeral and patchy resources have to regularly update their information about profitable sites. For many tropical amphibians, widespread, scattered breeding pools constitute such fluctuating resources. Among tropical amphibians, poison frogs (Dendrobatidae) exhibit some of the most complex spatial and parental behaviors - including territoriality and tadpole transport from terrestrial clutches to ephemeral aquatic deposition sites. Recent studies have revealed that poison frogs rely on spatial memory to successfully navigate through their environment. This raises the question of when and how these frogs gain information about the area and suitable reproductive resources. To investigate the spatial patterns of pool use and to reveal potential explorative behavior, we used telemetry to follow males of the territorial dendrobatid frog Allobates femoralis during tadpole transport and subsequent homing. To elicit exploration, we reduced resource availability experimentally by simulating desiccated deposition sites. We found that tadpole transport is strongly directed towards known deposition sites and that frogs take similar direct paths when returning to their home territory. Frogs move faster during tadpole transport than when homing after the deposition, which probably reflects different risks and costs during these two movement phases. We found no evidence for exploration, neither during transport nor homing, and independent of the availability of deposition sites. We suggest that prospecting during tadpole transport is too risky for the transported offspring as well as for the transporting male. Relying on spatial memory of multiple previously discovered pools appears to be the predominant and successful strategy for the exploitation of reproductive resources in $A$. femoralis. Our study provides for the first time a detailed description of poison frog movement patterns during tadpole transport and corroborates recent findings on the significance of spatial memory in poison frogs. When these frogs explore and discover new 
reproductive resources remains unknown. 
1 Relying on known or exploring for new? Movement patterns and reproductive resource use in a

2 tadpole-transporting frog

3

4 Kristina B. Beck ${ }^{1,2}$, Matthias-Claudio Loretto ${ }^{2}$, Max Ringler ${ }^{3,4}$, Walter Hödl ${ }^{4}$, Andrius

5 Pašukonis ${ }^{2,5}$

6

$7 \quad{ }^{1}$ Department of Behavioural Ecology and Evolutionary Genetics, Max Planck Institute for

8 Ornithology, Eberhard-Gwinner-Str. 7, 82319 Seewiesen, Germany

92 Department of Cognitive Biology, University of Vienna, Althanstrasse 14, 1090 Vienna, Austria

$10{ }^{3}$ Department of Ecology and Evolutionary Biology, University of California, 621 Charles E.

11 Young Drive South, CA 90095, Los Angeles, USA

$12{ }^{4}$ Department of Integrative Zoology, University of Vienna, Althanstrasse 14, 1090 Vienna,

13 Austria

14 5FAS Center for Systems Biology, Harvard University, 52 Oxford Street, MA 02138,

15 Cambridge, USA

16

17 Corresponding authors:

18 Kristina B. Beck ${ }^{1,2}$

19 Email: kbeck@orn.mpg.de 


\section{Abstract}

27 Animals relying on uncertain, ephemeral and patchy resources have to regularly update their information about profitable sites. For many tropical amphibians, widespread, scattered breeding pools constitute such fluctuating resources. Among tropical amphibians, poison frogs (Dendrobatidae) exhibit some of the most complex spatial and parental behaviors - including territoriality and tadpole transport from terrestrial clutches to ephemeral aquatic deposition sites. Recent studies have revealed that poison frogs rely on spatial memory to successfully navigate their environment. This raises the questions of when and how these frogs gain information about the area and suitable reproductive resources. To investigate the spatial patterns of pool use and to reveal potential explorative behavior, we used telemetry to follow males of the territorial dendrobatid frog Allobates femoralis during tadpole transport and subsequent homing. To elicit exploration, we reduced resource availability experimentally by simulating desiccated deposition 38 sites.

39 We found that tadpole transport is strongly directed towards known deposition sites and that frogs take similar direct paths when returning to their home territory. Frogs move faster during tadpole transport than when homing after the deposition, which probably reflects different risks and costs during these two movement phases. We found no evidence for exploration, neither during transport nor homing, independent of the availability of deposition sites. We suggest that prospecting during tadpole transport is too risky for the transported offspring as well as for the transporting male. Relying on spatial memory of multiple previously discovered pools appears to be the predominant and successful strategy for the exploitation of reproductive resources in $A$. 
47 femoralis. Our study provides for the first time a detailed description of poison frog movement 48 patterns during tadpole transport and corroborates recent findings on the significance of spatial memory in poison frogs. When these frogs explore and discover new reproductive resources remains unknown.

\section{Introduction}

In a dynamic environment resource availability changes in time and space which has major influences on animal movement decisions (Milner-Gulland, Fryxell \& Sinclair, 2011; Bell, 2012). Animals that rely on unpredictable, ephemeral, and patchy resources have to explore their environment regularly (Roshier, Doerr \& Doerr, 2008). Updating information on profitable resources can be achieved by exploring unknown areas to collect new information, by frequently visiting already known patches to affirm the availability of resources, or by prospecting for new resources within familiar areas (Real, 1981; Eliassen et al., 2009; Díaz et al., 2013). However, exploration comes at a cost of the time spent searching, which conflicts with other fitness-related activities such as territory defense (cf. Ydenberg \& Krebs, 1987) and advertising for mates (Thomas et al., 2003). Exploration also increases the exposure to sit-and-wait predators and thus overall predation risk (Stamps, 1995). Thus, animals depending on fluctuating resources need to find a balance between relying on known resources and prospecting for new ones (MilnerGulland, Fryxell \& Sinclair, 2011).

Most amphibians depend on aquatic sites for breeding, making this taxon particularly suitable for investigating how animals deal with varying availability, stability and distribution of resources. Amphibians exhibit a great diversity of reproductive strategies ranging from explosive breeders that gather at large ponds for synchronized spawning, to prolonged breeders with terrestrial 
70 clutches that use small widespread pools for tadpole development (Duellman \& Trueb, 1994;

71 Crump, 2015). Tropical amphibians, in particular, are renowned for the variety of aquatic sites

72 that they use for reproduction (Wells, 2007). Despite the overall large amount of rainfall,

73 seasonal variability can have a strong impact on the availability of breeding resources and thus

74 on the reproductive success of tropical amphibians (Aichinger, 1987; Bertoluci \& Rodrigues,

75 2002; Gottsberger \& Gruber, 2004). During heavy rainfall, potential breeding sites such as small

76 pools in the ground can appear within hours. However, desiccation also happens rapidly due to

77 the high environmental temperatures. To date, it remains mostly unknown how tropical

78 amphibians deal with the uncertainty of breeding sites, and which mechanisms they use to find

79 these scattered resources.

80 The Neotropical poison frogs (Dendrobatidae) exhibit a variety of complex spatial behaviors

81 such as territoriality, tadpole transport, and offspring provisioning (Weygoldt, 1987; Pröhl, 2005;

82 Lötters, 2007). The complex parental behavior in this group of frogs has attracted a considerable

83 amount of research (e.g. (Brown, Morales \& Summers, 2008; Dugas et al., 2015; Ringler et al.,

84 2015; Schulte \& Summers, 2017); for reviews see (Wells, 2007; Summers \& Tumulty, 2013;

85 Roland \& O’Connell, 2015)). However, the associated movement patterns and the factors

86 shaping them have rarely been quantified and remain poorly understood (but see (Summers,

87 1990; Brown, Morales \& Summers, 2009; Ringler et al., 2013)). Most poison frogs show site

88 fidelity to their territory and shuttle their larvae from terrestrial clutches to widespread,

89 ephemeral deposition sites, where the larvae complete their development (e.g. Ameerega

90 trivittata and A. femoralis, (Roithmair, 1992); Ranitomeya imitator and R. variabilis (Brown,

91 Morales \& Summers, 2009); R. reticulata (Werner et al., 2010); Colostethus panamansis (Wells,

92 1980); Dendrobates auratus (Summers, 1990); D.leucomelas and Oophaga histrionica 
93 (Summers, 1992); for reviews see (Weygoldt, 1987; Pröhl, 2005; Wells, 2007)). When

94 transporting their offspring, frogs need to know when and where to go for suitable water bodies

95 that are persistent enough to allow larval development, but ephemeral enough to minimize

96 predator abundance (cf. Murphy, 2003; Lehtinen, 2004). Recent studies have shown that poison

97 frogs can use flexible learning strategies in spatial tasks in captivity (Dendrobates auratus, (Liu

98 et al., 2016)) and rely on prior experience to successfully return home after translocation

99 (Allobates femoralis, (Pašukonis et al., 2013, 2014a)) and to find tadpole deposition sites in the

100 field (Pašukonis et al., 2016). Further, two poison frog species have been shown to use spatial

101 rather than direct cues for offspring recognition (Stynoski, 2009; Ringler et al., 2016b). Together

102 these results suggest that poison frogs rely on spatial memory to successfully navigate in their

103 environment, which raises the question of when and how these frogs gain information about the

104 area and in particular how they update information on the availability of their reproductive

105 resources. To date, exploratory behavior has only been reported in two poison frog species in the

106 form of prospecting trips after tadpole deposition, between tadpole transport events $(D$.

107 auratus,(Summers, 1989)) or prior to tadpole deposition (female Oophaga pumilio, (Brust, 108 1990)). However, the detailed movements during transport and exploration have not been

109 quantified for any poison frog species. In this study, we attempted to fill this knowledge gap by

110 tracking the well-studied poison frog Allobates femoralis during tadpole transport.

111 Allobates femoralis is a small territorial poison frog with predominantly male tadpole transport

112 (Ringler et al., 2013). Males spread their tadpoles across multiple, scattered aquatic sites; it has

113 been suggested that this approach increases offspring survival (Erich et al., 2015). Their

114 dependency on unpredictable resources and experience-based navigation make $A$. femoralis an

115 ideal study species to address questions concerning the mechanisms and timing of environmental 
116 exploration and learning. The demonstrated ability of $A$. femoralis to navigate to locations with

117 high spatial precision (Pašukonis et al., 2014a,b, 2016) makes it easier to interpret their

118 movement patterns, as it suggests that non-directed movement in the local area is more likely to

119 be exploratory behavior than an inability to orient in space. Since tadpole transport constitutes

120 the most prominent long-distance movement in A. femoralis (Ringler, Ursprung \& Hödl, 2009;

121 Ringler et al., 2013) it has been postulated that the frogs update their knowledge about the area

122 by exploring during tadpole transport and subsequent homing (Pašukonis et al., 2013, 2014b).

123 During the tadpole transport male frogs usually leave their territory, which provides them with a 124 chance to gain information on resource location and quality. However, such exploration during 125 tadpole transport would result in a trade-off between the potential benefits gained and the costs 126 related to searching behavior. During the breeding season, male A. femoralis are mostly found in 127 their territories, calling to attract females and to repel competing males (Kaefer et al., 2012). 128 Leaving the territory to explore would increase the risk of losing mating opportunities, losing the 129 entire territory, and can increase energetic expenditure as well as the risk of predation (e.g., 130 Wolf, Hainsworth \& Gill, 1975; Townsend, 1986; Roithmair, 1992). Tadpole transport consists 131 of two phases: first, shuttling the tadpoles until deposition, then homing back to the territory. 132 Exploratory behavior on the way to known deposition sites would also incur potential costs for 133 the offspring being transported, such as increased risk of desiccation (Downie et al., 2005), 134 whereas during homing it would only incur costs for the male. Thus, the net benefit of 135 prospecting for new deposition sites during homing should be higher, which might be reflected 136 in frog movement patterns.

137 In this study we quantified the movement patterns associated with tadpole transport and factors 138 that potentially influence them: attraction to cues originating from the pools, pool desiccation, 
139 and the weather. We used telemetry to follow transporting male A. femoralis towards artificial 140 deposition sites and back to their territory. To examine whether the frogs performed any 141 exploratory behavior we attempted to induce exploration by removing artificial pools to simulate 142 desiccation. We predicted that tadpole carriers would show fast, directional movement to known 143 pools, as we expected them to aim at reducing potential costs for the transported offspring and to 144 tend to perform exploratory detours on the way back to their territories. Further, we expected 145 frogs encountering a location where a pool had been removed before deposition to be more likely 146 to perform exploratory detours and to continue visiting other deposition sites to update their 147 information on pool availability.

149 Materials \& Methods

150 Study species and area

151 Allobates femoralis is a small diurnal frog (snout-urostyle length approximately $25 \mathrm{~mm}$ ) 152 common throughout Amazonia and the Guiana Shield (Amézquita et al., 2009). During the rainy 153 season males occupy territories (average defended area: $151.13 \mathrm{~m}^{2}$ (Ringler et al., 2011)) which 154 they advertise by calling and defend for up to several months (Roithmair, 1992; Ringler, 155 Ursprung \& Hödl, 2009). Mating and oviposition of approximately 20 eggs take place in the leaf 156 litter inside the male's territory (Roithmair, 1992; Ringler et al., 2012). After 15-20 days of 157 development, the male revisits the clutch, allows the tadpoles to wriggle onto his back, and 158 transports them to widely distributed deposition sites. On average, males are found with 8 159 tadpoles when transporting (range 1-25, cf., Ringler et al., 2013), and they can deposit them at 160 several pools (Erich et al., 2015). Females will transport the offspring only when males disappear 161 (Ringler et al., 2015). The frogs use a variety of small to medium-sized terrestrial water bodies 
162 such as rain-flooded depressions, holes in fallen trees, or palm bracts for tadpole deposition, and

163 recent tracking revealed that $A$. femoralis remember the location of at least six different pool

164 sites (Pašukonis et al., 2016). Aquatic deposition sites constitute a limiting resource for $A$.

165 femoralis, and frogs readily use artificial pools when provided in their natural habitat (Ringler,

166 Hödl \& Ringler, 2015).

167 We carried out the study from 18 January-12 March 2015 in a lowland rainforest on a 5 hectare 168 river island near the "Camp Pararé" field site at the CNRS "Nouragues Ecological Research 169 Station" in the Nature Reserve "Les Nouragues”, French Guiana ( $\left.3^{\circ} 59^{\prime} \mathrm{N}, 52^{\circ} 35^{\prime} \mathrm{W}\right)$ (Bongers et 170 al., 2013; Ringler et al., 2016). All necessary permits were provided by the Centre National de la 171 Recherche Scientifique (CNRS) and by the Direction Régionale de l'Environnement, de 172 l'Aménagement et du Logement (DEAL: ARRETE n²011-44/DEAL/SMNBSP/BSP). The 173 island population was established by introducing 1800 genotyped $A$. femoralis tadpoles from a 174 nearby population in 2012 (Ringler, Mangione \& Ringler, 2014) that were released in artificial 175 pools (volume $\sim 12$, inter-pool distance $\sim 10 \mathrm{~m}$ ). In 2013 , the pools were rearranged in a cross176 shaped array of 13 pools (inter-pool distance $\sim 20 \mathrm{~m}$ ). At the beginning of our study in 2015 we 177 removed every second pool to experimentally simulate dried-up water bodies, leaving 8 pools 178 available (Fig.1). Occasionally, tadpole carriers also used natural deposition sites such as small 179 flooded depressions and burrows on the forest floor. In total, we recorded four such natural sites 180 which temporarily filled with water, depending on the weather conditions, and which were 181 visited by tadpole-transporting frogs during our study (Fig.1).

183 Territory sampling 
184 To determine male territories, we continuously scanned the area for calling males during our

185 study. All frogs were caught in transparent plastic bags, photographed and individually identified

186 by their unique ventral coloration pattern (Ringler, Mangione \& Ringler, 2014) using the pattern

187 matching software Wild-ID (Bolger et al., 2011). We determined sex based on calling behavior

188 and the presence (male) or absence (female) of a vocal sac. We recorded exact capture positions

189 on a detailed GIS background map (Ringler et al., 2016a) using tablet PCs (WinTab 8, Odys)

190 with a mobile GIS software (ArcPad 10, ESRI). To calculate the center of the territory for each

191 male, we only used data points where males displayed territorial behavior (calling, courtship, 192 aggressive approach).

194 Tadpole carrier tracking

195 Because $A$. femoralis clutches are difficult to find and the timing when the male picks up the 196 tadpoles is variable (personal observation S. Weinlein), we focused our search effort on finding 197 frogs already transporting tadpoles, mostly by searching around known deposition sites.

198 Sampling was done every day between 0700 and $1300 \mathrm{~h}$ as tadpole transport mainly occurs in the 199 morning (Aichinger, 1987; Ringler et al., 2013). We caught the tadpole carriers in transparent 200 plastic bags, photographed them for identification, and recorded their exact position on the GIS 201 map. We counted the number of transported tadpoles, and when some tadpoles fell off during 202 catching and handling, we placed them on the male's back again.

203 Before the release, we equipped transporting males with a transponder attached to a waistband 204 (Fig. S1). The entire procedure took a few minutes and did not disrupt tadpole transport or 205 deposition behavior regardless of whether the tadpoles were manipulated or not. We followed 206 tagged tadpole carriers using the harmonic direction-finding (HDF) telemetry technique. This 
207 system consists of a passive reflector/transponder, which is attached to the animal and an active

208 directional transceiver, which emits and then receives the reflected radio signal. It allows smaller

209 animals to be tracked than would be possible by conventional active radio tracking (Mascanzoni

210 \& Wallin, 1986; Rowley \& Alford, 2007), and it has been successfully used in A. femoralis

211 (Pašukonis et al., 2014a,b). We fitted the tags using a silicon tube $2 \mathrm{~mm}$ in diameter, forming a

212 waistband with an additional strap between the hind legs to prevent the tag from rotating (Fig.

213 S1). Both parts were fixed with a cotton thread, which would break and release the waistband

214 after approximately two to three weeks (personal observation KB, AP) in case an individual was

215 not recaptured. The waistbands carried a small diode beneath a color-coded seal and a T-shaped

216 dipole antenna made of flexible, coated wire. The long end $(\sim 12 \mathrm{~cm})$ of the antenna dragged

217 freely behind the moving frog while the short end $(\sim 2 \mathrm{~cm})$ was secured inside the waistband. As

218 A. femoralis is strictly diurnal, we only tracked frogs during daylight hours (0700-1900 h),

219 relocating each individual and recording their position every 30-60 min. We followed each frog

220 until all tadpoles had been deposited and the male had returned to his territory, where the tag was

221 removed. We assumed that the frogs had returned when they approached locations at which they

222 had previously displayed territorial behavior. During tracking we tried to minimize disturbance

223 by carefully approaching the signal source while searching with the transceiver until the frog was

224 visually spotted or the origin of the signal could be narrowed down to less than $1 \mathrm{~m}$. We

225 approached individual frogs from different directions so as to not influence or bias their

226 movement in any direction. Occasional disturbances during tracking only influenced our

227 measurements of the directionality of long distance movements minimally, because $A$. femoralis

228 responds to disturbance by immediately hiding in the leaf litter rather than fleeing over longer

229 distances (personal observation KB, MR, AP). We caught tagged individuals when they had not 
230 moved for more than a day to check for possible issues such as skin injuries - in a single case we

231 immediately removed the tag. In one case without movement for more than two days but without

232 apparent injuries we also removed the tag to minimize any potential long-term effects on

233 behavior.

234

235 Tracking data

236 We handled and visualized spatial data in the GIS software ArcGIS10 (ESRI) after projecting

237 (UTM-zone 22N, WGS1984), and all analyses were performed in the statistical software R

238 version 3.2.0 (Team, 2014). We split the full trajectories of tracked frogs into tadpole transport

239 (TT) from the first encounter point to the last deposition site, and homing trajectories (HT), from

240 the last deposition site back to the home territory. Movement distance, duration, and speed were

241 calculated for each TT and HT. For individuals that took more than one day to complete

242 deposition and/or homing, we excluded the nights (-12 $\mathrm{h}$ per night) to estimate the average time

243 they were moving during tadpole transport. In most cases, the observed TT did not cover the full

244 TT as the frogs were encountered on their way to the pools or in their close vicinity. We

245 excluded individuals encountered immediately before tadpole deposition (frogs already present

246 at a pool or individuals with fewer than 2 tracking locations recorded before reaching the pool)

247 from the analysis of TT trajectories. We interpolated the total distances of TTs by approximating

248 the missing part from the territory center until the first encounter location by a straight-line to 249 obtain minimum-distance estimates (see Fig. 2).

250

251 Influence of tadpoles on movement speed: We created a generalized linear mixed model 252 (GLMM) to test the effects of tadpole presence (TT vs. HT) on the movement speed of frogs 
253 (family $=$ gamma, link = logit). As response variable, we used the average speed per TT and HT,

254 as explanatory variable "tadpoles present" (yes/no), and individual frog ID as random factor to

255 account for repeated trajectories of the same individuals.

256

257 Influence of weather on movement speed: Since frog activity varies throughout the day and 258 depends on weather conditions (Bellis, 1962; Brooke, Alford \& Schwarzkopf, 2000), we 259 investigated potential effects of the weather on the frogs' movement speed using temperature and 260 rainfall measurements, both obtained from an above-canopy weather station (Nouraflux: rainfall 261 sensor Campbell ARG100, temperature sensor Vaisala HMP155A). In contrast to the previous 262 model, where the focus was on certain trajectory sections (TT and HT), we focused on $3 \mathrm{~h}$ 263 intervals here to investigate variations in the frogs' activity (here: movement speed). The $3 \mathrm{~h}$ 264 intervals represent four potentially different daily activity periods in $A$. femoralis, with tadpole 265 transport happening predominately in the morning, low activity around noon, high calling 266 activity during the afternoon, and high calling activity and most female-male interactions (e.g., 267 courtship) in the evening (personal observation by all authors; see also (Kaefer et al., 2012; 268 Ringler et al., 2013)). We used a GLMM (family = gamma, link = logit), with speed as response variable, and the explanatory variables "tadpoles present" (yes/no), "time of the day" (split in

270 four $3 \mathrm{~h}$ intervals: 0700-1000, 1000-1300, 1300-1600, 1600-1900 h), average "temperature" for 271 each corresponding interval, and cumulative "rain" in millimeters during each interval. Since this 272 analysis is not within the main focus of this study, we present the results in the supplemental 273 information (Table S1, S2).

274

$275 \underline{\text { Pool visits }}$ 
276 We defined a pool visit as frogs actually entering a potential deposition site (position either on/in

277 a filled pool or on the removed/dried out pool location). For each tadpole carrier, we recorded all

278 potential tadpole deposition sites visited (available/removed artificial pool or available/dried-out

279 natural site), and whether tadpole deposition occurred at the available pools or not. To test

280 whether frogs explored further pools after the complete deposition of their offspring, we

281 recorded for each location whether there were tadpoles still present on their back or not. If frogs

282 moved to further pools without tadpoles on their back, we considered this to be exploratory

283 behavior. In addition, we calculated the average number of deposition sites the frogs visited

284 (available/removed artificial pool or available/dried-out natural site) per tadpole transport. We

285 excluded trajectories with only one final deposition site and no detailed TT.

287 Movement precision

288 To investigate whether frogs explored the surrounding area by taking additional detours, we 289 estimated the precision of the frogs' orientation towards the upcoming pools during TTs, and towards the territory during the HTs. To estimate navigation precision, we calculated three different parameters: (1) the straightness coefficient (SC) of the trajectory, (2) the average angular deviation between the ideal orientation angle and consecutive tracking locations, and (3) the average normal distance of tracking locations from the straight-line path. The SC is defined as the ratio between the straight-line distance to the respective goal and the actual path distance. $\mathrm{SC}$ ranges from 0 to 1 with 1 indicating a perfectly straight trajectory. The angular deviations were measured as the absolute angular difference between the ideal direction (angle from each tracking location to the respective goal) and the actual direction of the individual frog's movement (angle from each tracking location to the next one). For the distance of the frog's 
299 movement from the straight-line path, we calculated the perpendicular deviation of each tracking

300 location from the straight path. While the SC takes into account the entire trajectory at once, the

301 average angular deviations describe the movement decisions from location to location, and the

302 distance from the straight-line path assesses the frog's position in relation to the straight line for

303 every location. We calculated the mean angular deviation and distance from the straight-line path

304 by averaging all values per TTs and HTs in order to have three precision measurements per TTs 305 and HTs.

306 We tested for significant goal-directed orientation using absolute angles calculated with the

307 "as.ltraj" function from the package "adehabitatLT" (Calenge, 2015) per TTs and HTs using

308 Rayleigh tests with the package "circular" (Agostinelli \& Lund, 2011).

309

310

Influence of pool availability on movement precision: In addition, we tested whether the

precision during TTs differed (for example resulting from olfactory cues from the water), when tadpole carriers approached an available deposition site (artificial or natural pool) or an unavailable pool site (removed or desiccated). Therefore, we compared the precision of TTs (SC, average angular deviation and average distance from the straight line path per trajectory) of frogs that were heading towards available and non-available pools. We used different GLMMs with the "SC" (family = beta, link = logit), "average angular deviation" (family = gamma, link = logit) and "average distance to the straight-line path" (family = gamma, link = logit) as response variable. For all three models, we used "heading towards an available vs. non-available pool" as explanatory variable and individual frog ID as a random effect.

Finally, we investigated potential differences in precision along the tracked HTs between frogs 
322 dried-out water bodies) during prior tadpole transport. For the analysis, we used different linear

323 mixed models (LMM), with "average angular deviation" and "average distance from the straight-

324 line path" as response variable and a GLMM (family = beta, link = logit) with "SC" as response

325 variable. For all three models, we used "removed pool encountered during prior tadpole

326 transport" (yes/no) as explanatory variable and the individual frog ID as random factor to

327 account for repeated trajectories of the same individuals.

328

$329 \underline{\text { Model selection }}$

330 All the full models but one contained only a single explanatory variable, which was a binary

331 factor. We compared these models with the corresponding null (intercept) model based on the

332 second-order form of Akaike's information criterion (AICc; (Hurvich \& Tsai, 1989)). No

333 difference between the full model and the null model (i.e. $\triangle \mathrm{AICc} \leq 2)$ indicates that the variation

334 of the response variable is not explained better by the full model than by the null model

335 (Burnham \& Anderson, 2002). If this is the case the null hypothesis is supported and we

336 therefore do not present the model parameters in the results. For the model with several

337 explanatory variables we created all possible candidate models (all-subset modeling) following

338 the information-theoretic approach (Burnham \& Anderson, 2002). We ranked them according to

339 their AICc values and selected those within $\triangle \mathrm{AICc} \leq 2$ with respect to the top-ranked model. We

340 estimated parameters for each explanatory variable included in the $\triangle \mathrm{AICc} \leq 2$ subset by model

341 averaging (following Burnham \& Anderson, 2002).

342 All models were calculated using the R packages "lme4" (Bates \& Maechler, 2010) or

343 "glmmADMB" (Bolker et al., 2014), and the package "MuMIn" (Bartoń, 2013) for model 344 averaging. 


\section{Results}

347 Frog sampling and movement analysis

348 During the study period, we captured 67 individual males a total of 658 times. 408 captures were associated with male territorial behavior and were used to calculate territory centers (Fig.1). We observed 50 tadpole transports by 30 males and tagged 20 individuals, which allowed us to track 28 tadpole transports. From all tagged frogs, we used the TTs and/or HTs of 16 individuals for movement analysis: $\mathrm{n}=15$ TTs from 10 individuals (including five individuals with 2 TTs each); $\mathrm{n}=22$ HTs from 16 individuals, (including one individual with 3 HTs and four individuals with 2 HTs each). Other trajectories were excluded because some individuals had either not moved further than $5 \mathrm{~m}$ for two days $(\mathrm{n}=1)$, had an injury $(\mathrm{n}=1)$, were predated on by a spider $(\mathrm{n}=1)$, or the entire tadpole transport took place inside their territory $(n=1)$. All averaged values (i.e., distance, time and speed) were estimated by first averaging per trajectory section (TT and HT), followed by calculating the overall average from all TTs and HTs.

Summing up the entire trajectory (interpolated start $+\mathrm{TT}+\mathrm{HT} ; \mathrm{n}=14,10$ individuals) frogs moved an average of $141.73 \mathrm{~m}(\mathrm{sd}=68.87 \mathrm{~m}$, range $=59.94-276.01 \mathrm{~m})$ and were tracked for an average of $17.62 \mathrm{~h}(\mathrm{sd}=14.01$, range $=6.42-58.4 \mathrm{~h}$, nights excluded $)$. Tracked TT $(\mathrm{n}=15,10$ individuals, see Fig. 2) covered a distance of $56.34 \mathrm{~m}(\mathrm{sd}=38.09 \mathrm{~m}$, range $=4.93-141.37 \mathrm{~m})$ on average. The interpolated path was $39.21 \mathrm{~m}(\mathrm{sd}=24.72 \mathrm{~m}$, range $=0-95.16 \mathrm{~m}$, for $\mathrm{n}=12,7$ individuals) on average, adding up to an average distance of $87.71 \mathrm{~m}(\mathrm{sd}=40.29 \mathrm{~m}$, range $=$ 35.32-166.43 m) for the whole TT. The elapsed time until all tadpoles were deposited was $5.55 \mathrm{~h}$ $(\mathrm{sd}=2.7 \mathrm{~h}$, range $=2.08-13.25 \mathrm{~h}$, nights were excluded for $\mathrm{n}=1)$ on average. The speed during tracked TTs was on average $10.16 \mathrm{~m} / \mathrm{h}$, reaching a maximum of $17.91 \mathrm{~m} / \mathrm{h}$ (averaged over the 
368 entire TTs, distance $=55.16 \mathrm{~m}$, time $=3.08 \mathrm{~h}$; for further details see Table S3). During HTs,

369 male frogs moved an average distance of $54.57 \mathrm{~m}(\mathrm{sd}=29.63 \mathrm{~m}$, range $=15.98-123.46 \mathrm{~m}, \mathrm{n}=$

37022,16 individuals, see Fig. S2) and the average time elapsed until their return to the territory was

$37110.78 \mathrm{~h}(\mathrm{sd}=10.38 \mathrm{~h}$, range $=1-49.9 \mathrm{~h}$, nights were excluded for $\mathrm{n}=10)$. Speed during homing

372 was $7.22 \mathrm{~m} / \mathrm{h}$ on average with a maximum of $22.16 \mathrm{~m} / \mathrm{h}$ (averaged over the entire HTs, distance

$373=22.16 \mathrm{~m}$, time $=1 \mathrm{~h}$; for further details see: Table S4). The movements during the TTs and the

374 HTs were characterized by stop-and-go phases varying in speed (range of speed from one

375 tracking location to the next one $=0-70.12 \mathrm{~m} / \mathrm{h}$, for further details see Figure S3 and S4).

376 Frogs moved significantly faster when tadpoles were still present compared to the subsequent

377 homing (GLMM estimates \pm standard errors: with tadpoles $0.132 \pm 0.015$; without tadpoles

$3780.092 \pm 0.017 ; \mathrm{p}=0.02$; see also Figure 3). Results from our model investigating effects of 379 weather on the movement speed of frogs can be found in the supplemental information: Table $380 \mathrm{~S} 1, \mathrm{~S} 2)$.

381

382 Pool visits

383 We recorded 49 pool visits during 28 TTs (20 tagged individuals) including all artificial and 384 natural, available and removed/dry pools. Frogs carried on average 8.5 tadpoles $(\mathrm{sd}=4.9, \mathrm{n}=27$; 1 excluded) and were never observed to visit further pools after depositing all their tadpoles. In 386 25 of the 28 TTs, successful deposition of tadpoles was recorded. The remaining 3 individuals 387 either lost the tadpoles overnight $(n=1)$, were predated on by a spider $(n=1)$ or disappeared 388 during tracking $(n=1)$. From the 49 pool visits recorded, deposition occurred in 29 cases 389 (artificial pools $=26$ times, natural deposition sites $=3$ times) and no deposition took place in 20 390 cases (removed artificial pool $=11$ times, dry natural pool $=6$ times, available artificial pool $=3$ 
391 times). On average, the first observed pool visited by each frog $(\mathrm{n}=28)$ was $41.07 \mathrm{~m}$ (range $=$ 392 2.1-98.33 m) away from the territory center. During the tracked TTs, male frogs visited an 393 average of 2.4 depositions sites per transport event $(n=15$, range $=1-4$, including removed and 394 desiccated pools). However, we cannot exclude that frogs visited other deposition sites before we 395 encountered them.

\section{$\underline{\text { Movement precision }}$}

398 Frog movement was strongly directed towards potential deposition sites and the home territory 399 for TTs and HTs, respectively (see Fig. 2, 4 and Fig. S2). We only used tracks with more than 400 three locations for the analysis of directionality. The tadpole carriers $(n=14,10$ individuals; 1 401 excluded) moved directly to and between potential deposition sites with an average straightness 402 coefficient of $0.83(\mathrm{sd}=0.13)$, an average angular deviation of $24.52^{\circ}\left(\mathrm{sd}=36.58^{\circ}\right.$; Rayleigh test $\mathrm{p}<0.001)$ and an average linear deviation of $2.9 \mathrm{~m}(\mathrm{sd}=4.02)$ from the straight-line path. On 404 their way back to the home territory, frogs $(n=22,16$ individuals $)$ reached an average straightness coefficient of $0.87(\mathrm{sd}=0.12)$ and moved with an average angular deviation of 406 $32.28^{\circ}\left(\mathrm{sd}=42.58^{\circ}\right.$; Rayleigh $\left.\mathrm{p}<0.001\right)$ from the ideal path and an average linear deviation of $2.04 \mathrm{~m}(\mathrm{sd}=2.03)$.

Movement precision during TTs: None of the models with SC, average angular deviation or 409 average distance to the straight-line path as response variable and heading towards an available or unavailable pool as explanatory variable improved the AICc compared to their corresponding 411 null model. Thus, we could not find any difference in the frog's movement behavior when 412 encountering a removed or available pool (Table S5). 
413 Movement precision during homing: The two models with the response variables SC or average

414 distance to straight line and heading towards an available or unavailable pool as explanatory

415 variable did not improve the AICc compared to their corresponding null model. For the model

416 with average angular deviation as response variable, the AICc of the full model was lower

417 compared to the corresponding null model $(\triangle \mathrm{AICc}=2.59)$, but there was no difference between

418 the levels of the explanatory variable (GLMM estimates \pm standard errors: heading towards an

419 available pool $28.733 \pm 4.860$; heading towards a non-available pool $29.580 \pm 6.625 ; \mathrm{p}=0.9$ ).

420 Overall, this indicates that there is no difference during homing between frogs that did or did not

421 encounter an unavailable deposition site during tadpole transport (Table S6).

422

423 Discussion

424 Movement patterns

425 In our study, we quantified movements of tadpole-transporting frogs, but we did not observe any 426 exploratory behavior of $A$. femoralis during tadpole transport or subsequent homing. Males

427 exhibited highly directed movement towards deposition sites and, in contrast to our predictions, 428 also on their way back to their home territory. Frogs moved faster when transporting the tadpoles 429 than when homing and we found no effect of pool presence (available or unavailable deposition 430 site) on the precision or speed of movement.

431

432 For breeding males, long distance movements can have many potential costs such as energy 433 expenditure, exposure to predation, lost mating opportunities, and the risk of losing the territory 434 altogether (Bell, 2012). Straight movement towards previously learned deposition sites and back 435 to the home territory minimizes both distance and time, thereby reducing such costs. During the 
436 TT these costs may even be higher, as offspring survival also has to be taken into account

437 (Downie et al., 2005), which might explain the increased speed during tadpole shuttling. During

438 the breeding season, particularly in the afternoons, male A. femoralis are mostly found in their

439 territories, calling to attract females and repel competing males (Kaefer et al., 2012). Male

440 mating success in A. femoralis is determined by the possession of a territory (Ursprung et al.,

4412011 ) and probably also by calling activity and territory size (Roithmair, 1992). Exploration

442 during the tadpole transport could decrease mating success and hence the individual fitness of

443 males. We suggest that the costs of exploratory behavior during tadpole transport outweigh

444 potential benefits for breeding males, and thus exploration is more likely to occur when males

445 are not currently defending a territory.

446

447 During the breeding season, new artificial pools are used for tadpole deposition within days or

448 weeks, indicating that at least some exploration occurs during the reproductive season ((Ringler,

449 Hödl \& Ringler, 2015); personal observation MR and AP). Territorial displacements, as well as

450 spontaneous territorial shifts, have been observed both within and between reproductive seasons

451 (Ringler, Ursprung \& Hödl, 2009), and are particularly common at the onset of reproduction

452 (personal observation MR, AP). Such shifts may provide opportunities to explore the

453 surrounding area and update the information on pool availability that are less costly. In addition,

454 very little is known about $A$. femoralis movements outside the breeding season. We have

455 regularly observed juveniles as well as adult frogs in the immediate vicinity of water-filled 456 artificial pools during dry periods, when calling and reproductive activity is low (personal

457 observation MR, AP). Sensitive learning phases during the juvenile stage are common in

458 vertebrates (Immelmann, 1975), but since adult frogs can establish new territories (Ringler, 
459 Ursprung \& Hödl, 2009) and discover new pools during the breeding season (Ringler, Hödl \&

460 Ringler, 2015), the spatial learning mechanism seems to be flexible and open-ended. In addition,

461 both complete pool desiccation during the dry season and disappearance of some pools over time

462 suggest that exploration during juvenile dispersal and the non-reproductive season alone are

463 unlikely to provide sufficient information to the frogs for efficient tadpole transport. Studying

464 juvenile dispersal and the adult movement patterns outside the breeding season, however, will be 465 necessary to fully understand when and how the frogs acquire new spatial information.

466 Furthermore, investigating the learning mechanisms underlying the spatio-cognitive capacity

467 could provide insights into its potential constraints and how animal movement is shaped (Fagan

468 et al., 2013).

469

470 We found that movement speed was significantly higher when tadpoles were still being carried

471 compared to the speed after tadpole deposition had occurred. As has been shown in another

472 poison frog species (Smith et al., 2006), the presence of tadpoles does not seem to inhibit the

473 locomotory performance of transporting frogs. We assume that overall costs during tadpole

474 transport are higher than during homing, as the survival of the transported offspring also has to

475 be accounted for. As a result, frogs appear to adjust their movements and, for instance, quickly

476 deposit their offspring to prevent the tadpoles from drying out (Downie et al., 2005). However,

477 why frogs are slower during homing still remains unclear. Since frogs do not appear to explore

478 during homing, faster homing should reduce the risk of losing mating opportunities (Roithmair,

479 1992; Ringler et al., 2013), or even the entire territory. Potential exhaustion after tadpole

480 deposition, time needed for homewards orientation or high risk of predation during fast

481 movement might explain slower movement during homing, but future studies need to examine 
482 these factors in more detail. All movements were in general characterized by stop-and-go phases

483 of varying duration and speed. Intermittent movement patterns can be found in many organisms

484 ranging from protozoans to mammals, and in a variety of behavioral contexts such as searching

485 or habitat assessment. Frequent stops could lead to perceptual benefits because animals then have

486 time to scan the area, and conspicuousness towards predators might be reduced (Kramer \&

487 McLaughlin, 2001). Hence, the stop-and-go locomotion pattern of male frogs during tadpole

488 shuttling and homing could be a further adaptation for orientation and resting, while reducing

489 risks related to continuous movement.

490

$491 \quad \underline{\text { Pool visits }}$

492 During the entire study, we never observed male frogs that encountered a removed artificial or 493 dry natural pool exhibiting any exploratory behavior after the deposition of tadpoles. Two 494 individuals that encountered an unavailable deposition site were observed during a second 495 tadpole transport event when they visited the very same unavailable pool. In contrast to our 496 predictions, the actual availability of potential deposition sites had little influence on the 497 movement patterns of male frogs, and no apparent updating of information concerning resource 498 availability during tadpole transport occurred. In our study, all frogs except one (which lost 499 tadpoles overnight) managed to find an available pool for deposition even if they had previously 500 encountered a removed or dry pool. Furthermore, we recorded one male visiting a natural pool 501 site that never held water during the entire study period and could only have been known as a 502 potential deposition site from previous years. These findings suggest that male frogs rely 503 predominantly on their spatial memory to find deposition sites and do not invest time and energy 504 in exploring further pools during tadpole transport. The availability of suitable breeding pools 
505 can change rapidly in the tropics as a result of sudden, heavy rainfalls or fast desiccation due to 506 strong solar radiation. Nevertheless, resource availability seems to be sufficiently stable for frogs

507 to rely on memory-based orientation strategies. Previously unavailable pools might turn into

508 available breeding resources after one heavy rainfall, whereas some pool locations remain the 509 same not only for the entire breeding season, but for several years at a time. Thus, frogs may 510 remember previously visited pools as having been available in the past and to be at least in 511 principal able to contain water. The best strategy might be to remember previous sites and visit 512 them repeatedly, even at the risk that they might have vanished since the last visit. Many nectar513 feeding species use similar strategies and primarily use spatial information to relocate flowers 514 over object-based cues (e.g., Hurly \& Healy, 2002; Thiele \& Winter, 2005; Carter, Ratcliffe \& 515 Galef, 2010). In a study on nectar-feeding bats (Glossophaga commissarisi) they could show that 516 flight approaches to feeders that were primarily guided by spatial memory were of shorter 517 duration than approaches that included object-based cues, indicating that there is a short-term 518 energy advantage to the spatial-memory strategy (Thiele \& Winter, 2005). Relying primarily on 519 spatial memory to find pools repeatedly is probably also more efficient than locating them based 520 on goal-associated cues.

522 We did not find any difference when comparing the precision and speed of frogs that moved 523 towards an available or unavailable deposition site, suggesting that pool-associated cues, such as 524 odor, do not play a major role in orientation towards the pools. This further supports evidence 525 that A. femoralis mainly uses suitable pools based on spatial memory (Pašukonis et al., 2016). 526 Olfaction, however, has been shown to play a role in poison frog pool choice (R. variabilis; 527 Schulte et al., 2011 and Schulte \& Lötters, 2014) and orientation (A. femoralis; Pašukonis et al., 
528 2016). In A. femoralis olfactory cues might especially play a role in the initial discovery and

529 evaluation of suitable deposition sites. Finally, other indirect cues, such as pool-associated

530 microhabitat (e.g., as in salamanders (Jenkins, McGarigal \& Timm, 2006)) or calls of

531 heterospecifics (e.g., as in newts (Diego-Rasilla \& Luengo, 2007)), might be used by tadpole-

532 transporting frogs to discover breeding sites. For example, transporting males of the poison frog

533 Dendrobates tinctorius were found to gather at sites of fresh treefalls, which often provide new

534 deposition sites (Rojas, 2015).

535 Recent tracking and genetic studies have revealed that $A$. femoralis remember the location of up

536 to six different pool sites (Pašukonis et al., 2016) and that frogs actively partition their offspring

537 across several water bodies as a possible reproductive bet-hedging strategy (Erich et al., 2015).

538 Our results corroborate these findings as tracked individuals usually visited and used two to three 539 deposition sites per tadpole transport event. Most frogs moved considerable distances beyond the 540 boundaries of their territory and often used pools that were not the closest ones to their territory.

541 However, we cannot entirely rule out that some of the movements we observed between multiple

542 pool sites were a byproduct of disturbance from tracking and handling. If tadpole distribution

543 over several sites improves offspring survival, then knowing more pool locations should have

544 direct fitness consequences. We speculate that this creates a trade-off between minimizing the

545 costs of tadpole transport and maximizing the potential benefits gained through offspring 546 partitioning over multiple learned sites (see Erich et al., 2015).

547

548 Conclusions

549 While it remains unknown when and how the poison frog $A$. femoralis collects information about 550 the surrounding area, we provide, for the first time, detailed information about the movement 
551 patterns during tadpole transport. We observed highly directional movement between territories

552 and pools as well as between pools, suggesting an advantage of quick tadpole transport and

553 homing over additional detours to explore the area. Future research should investigate in more

554 detail the costs and benefits of tadpole transport in order to understand the trade-offs shaping

555 movement strategies in such dynamic environments. Further, the mechanisms that allow poison

556 frogs to establish a spatial memory and orientate with such high precision in the rainforest

557 remain unknown.

558 Despite extensive capture-recapture studies (e.g., Brown, Morales \& Summers, 2009; Ringler,

559 Ursprung \& Hödl, 2009), and some tracking of A. femoralis after translocations (Pašukonis et al.,

560 2014a,b) and tadpole transport (Pašukonis et al., 2016), still very little is known about the natural

561 movement patterns of poison frogs and tropical amphibians in general. Tropical amphibians

562 exhibit a huge diversity in breeding strategies ranging from explosive breeders that gather in

563 ponds to prolonged breeders that depend on widespread, ephemeral pools for tadpole

564 development. This diversity and the dependence on water bodies for reproduction make tropical

565 amphibians a valuable study system to investigate how animals deal with varying resource

566 availability and how this shapes movement patterns. Our findings contribute to the knowledge of

567 spatial behavior in poison frogs and will hopefully encourage further research on movement

568 ecology of tropical amphibians.

569

570

571 Acknowledgments

572 We are grateful to the staff of CNRS Guyane and the Nouragues Ecological Research Station for

573 logistic support in the field and to Nicolas Perrin for providing the RECCO® transceiver. We 
574 also thank Rosanna Mangione and Steffen Weinlein for their help in the field, Gesche Westphal-

575 Fitch for proofreading and correcting language and style of the manuscript, Lisa Maria Schulte,

576 Rick Lehtinen, and one anonymous reviewer for constructive feedback on the manuscript.

577

578

579

580

581

582

583

584

585

586

587

588

589

590

591

592

593

594

595

596

\section{References}

Agostinelli C., Lund U. 2011. R package circular: Circular Statistics (version 0.4-3). CA:

Department of Environmental Sciences, Informatics and Statistics, Ca'Foscari University, Venice, Italy. UL: Department of Statistics, California Polytechnic State University, San Luis Obispo, California, USA:1

Aichinger M. 1987. Annual activity patterns of anurans in a seasonal neotropical environment. Oecologia 71:583-592

Amézquita A., Lima AP., Jehle R., Castellanos L., Ramos Ó., Crawford AJ., Gasser H., Hödl W. 2009. Calls, colours, shape, and genes : a multi-trait approach to the study of geographic variation in the Amazonian frog Allobates femoralis. Biological Journal of the Linnean Society 98:826-838

Bartoń K. 2013. MuMIn: multi-model inference. $R$ package version 1

Bates DM., Maechler M. 2010. lme4: Linear mixed-effects models using S4 classes. R package version $0.999375-36 / \mathrm{r} 1083$

Bellis ED. 1962. The influence of humidity on wood frog activity. American Midland Naturalist 68:139-148. DOI: $10.2307 / 2422640$

Bertoluci J., Rodrigues MT. 2002. Seasonal patterns of breeding activity of Atlantic Rainforest anurans at Boracéia, Southeastern Brazil. Amphibia Reptilia 23:161-168

Bolger DT., Vance B., Morrison TA., Farid H. 2011. Wild-id user guide: pattern extraction and 
matching software for computer-assisted photographic markrecapture analysis. Dartmouth

Bolker B., Skaug H., Magnusson A., Nielsen A. 2014. Getting started with the glmmADMB package: http://glmmadmb. r-forge. r-pro ject. org/glmmADMB. html.

601

602

603

604

605

606

607

608

609

610

611

612

613

614

615

616

617

618

619
Brooke PN., Alford RA., Schwarzkopf L. 2000. Environmental and social factors influence chorusing behaviour in a tropical frog: examining various temporal and spatial scales. Behavioral Ecology and Sociobiology 49:79-87

Brown JL., Morales V., Summers K. 2008. Divergence in parental care, habitat selection and larval life history between two species of Peruvian poison frogs: an experimental analysis. Journal of evolutionary biology 21:1534-1543

Brown JL., Morales V., Summers K. 2009. Home range size and location in relation to reproductive resources in poison frogs (Dendrobatidae): a Monte Carlo approach using GIS data. Animal Behaviour 77:547-554

Brust, D. G. 1990. Maternal brood care by Dendrobates pumilio: a frog that feeds its young. Ph.D. thesis, Cornell University

Burnham KP., Anderson DR. 2002. Model selection and multimodel inference: a practical information-theoretic approach. New York: Springer

Calenge C. 2015. Analysis of animal movements in R: the adehabitatLT Package

Carter GG., Ratcliffe JM., Galef BG. 2010. Flower bats (Glossophaga soricina) and fruit bats (Carollia perspicillata) rely on spatial cues over shapes and scents when relocating food. PloS one 5:e10808

Crump ML. 2015. Anuran Reproductive Modes: Evolving Perspectives. Journal of Herpetology $49: 1-16$ 
620 Díaz PC., Arenas A., Fernández VM., Martin S., Basilio AM. 2013. Behavioral Honeybee 621 cognitive ecology in a fluctuating agricultural setting of apple and pear trees. Behavioral 622 Ecology 24:1058-1067. DOI: 10.1093/beheco/art026

623 Diego-Rasilla FJ., Luengo RM. 2007. Acoustic orientation in the palmate newt, Lissotriton 624 helveticus. Behavioral Ecology and Sociobiology 61:1329-1335

625 Downie JR., Robinson E., Linklater-McLennan RJ., Somerville E., Kamenos N. 2005. Are there 626 costs to extended larval transport in the Trinidadian stream frog, Mannophryne trinitatis 627 (Dendrobatidae)? Journal of Natural History 39:2023-2034

628 Duellman WE., Trueb L. 1994. Biology of amphibians. JHU press

629 Dugas MB., Wamelink CN., Killius AM., Richards-Zawacki CL. 2015. Parental care is 630 beneficial for offspring, costly for mothers, and limited by family size in an egg-feeding 631 frog. Behavioral Ecology 27:476-483

632 Eliassen S., Jørgensen C., Mangel M., Giske J. 2009. Quantifying the adaptive value of learning 633 in foraging behavior. The American Naturalist 174:478-489. DOI: 10.1086/605370

634 Erich M., Ringler M., Hödl W., Ringler E. 2015. Brood-partitioning behaviour in unpredictable 635 environments: hedging the bets? Behavioral ecology and sociobiology 69:1011-1017. DOI:

636 $10.1007 / \mathrm{s} 00265-015-1913-1$

637 Fagan WF., Lewis MA., Auger-Méthé M., Avgar T., Benhamou S., Breed G., LaDage L., 638 Schlägel UE., Tang W., Papastamatiou YP. 2013. Spatial memory and animal movement. $639 \quad$ Ecology letters 16:1316-1329

640 Gottsberger B., Gruber E. 2004. Temporal partitioning of reproductive activity in a neotropical 641 anuran community. Journal of Tropical Ecology 20:271-280. DOI: https://doi.org/10.1017/S0266467403001172 
643 Hurly TA., Healy SD. 2002. Cue learning by rufous hummingbirds (Selasphorus rufus). Journal 644 of Experimental Psychology: Animal Behavior Processes 28:209

645 Hurvich CM., Tsai C-L. 1989. Regression and time series model selection in small samples.

646 Biometrika 76:297-307. DOI: 10.2307/2336663

647 Immelmann K. 1975. Ecological significance of imprinting and early learning. Annual Review of $648 \quad$ Ecology and Systematics 6:15-37

649 Jenkins CL., McGarigal K., Timm BC. 2006. Orientation of movements and habitat selection in 650 a spatially structured population of marbled salamanders (Ambystoma opacum). Journal of $651 \quad$ Herpetology 40:240-248

652 Kaefer IL., Montanarin A., Da Costa RS., Lima AP. 2012. Temporal patterns of reproductive 653 activity and site attachment of the brilliant-thighed frog Allobates femoralis from central 654 Amazonia. journal of Herpetology 46:549-554. DOI: http://dx.doi.org/10.1670/10-224

655 Kramer DL., McLaughlin RL. 2001. The behavioral ecology of intermittent locomotion.

656 American Zoologist 41:137-153. DOI: http://dx.doi.org/10.1668/0003-

657 1569(2001)041[0137:TBEOIL]2.0.CO;2

658 Lehtinen RM. 2004. Tests for competition, cannibalism, and priority effects in two phytotelm-

659 dwelling tadpoles from Madagascar 1. Herpetologica 60:1-13. DOI:

660 http://dx.doi.org/10.1655/02-88

661 Liu Y., Day LB., Summers K., Burmeister SS. 2016. Learning to learn : advanced behavioural fl 662 exibility in a poison frog. Animal Behaviour 111:167-172. DOI:

$663 \quad 10.1016 / j$.anbehav.2015.10.018

664 Lötters S. 2007. Poison frogs: biology, species and captive care. Chimaira

665 Mascanzoni D., Wallin H. 1986. The harmonic radar: a new method of tracing insects in the 
Milner-Gulland EJ., Fryxell JM., Sinclair ARE. 2011. Animal migration: a synthesis. Oxford University Press Oxford

669

670

671

672

673

674

675

676

677

678

679

680

681

682

683

684

685

686

687

688

Murphy PJ. 2003. Does reproductive site choice in a Neotropical frog mirror variable risks facing offspring? Ecological Monographs 73:45-67. DOI: 10.1890/00129615(2003)073[0045:DRSCIA]2.0.CO;2

Pašukonis A., Loretto M-C., Landler L., Ringler M., Hödl W. 2014a. Homing trajectories and initial orientation in a Neotropical territorial frog, Allobates femoralis (Dendrobatidae). Frontiers in Zoology 11:29. DOI: 10.1186/1742-9994-11-29

Pašukonis A., Ringler M., Brandl HB., Mangione R., Ringler E., Hödl W. 2013. The Homing Frog: High Homing Performance in a Territorial Dendrobatid Frog Allobates femoralis (Dendrobatidae). Ethology 119:762-768. DOI: 10.1111/eth.12116

Pašukonis A., Trenkwalder K., Ringler M., Ringler E., Mangione R., Steininger J., Warrington I., Hödl W. 2016. The significance of spatial memory for water finding in a tadpoletransporting frog. Animal Behaviour 116:89-98. DOI: http://dx.doi.org/10.1016/j.anbehav.2016.02.023

Pašukonis A., Warrington I., Ringler M., Hödl W. 2014b. Poison frogs rely on experience to find the way home in the rainforest. Biology letters 10:20140642. DOI: 10.1098/rsbl.2014.0642

Pröhl H. 2005. Territorial behavior in dendrobatid frogs. Journal of Herpetology 39:354-365. DOI: http://dx.doi.org/10.1670/162-04A.1

Real LA. 1981. Uncertainty and pollinator-plant interactions: the foraging behavior of bees and wasps on artificial flowers. Ecology 62:20-26. DOI: 10.2307/1936663

Ringler M., Hödl W., Ringler E. 2015. Populations, pools, and peccaries: simulating the impact 
689

690

691

692

693

694

695

696

697

698

699

700

701

702

703

704

705

706

707

708

709

710

711

of ecosystem engineers on rainforest frogs. Behavioral Ecology 26:340-349. DOI: https://doi.org/10.1093/beheco/aru243

Ringler M., Mangione R., Pašukonis A., Rainer G., Gyimesi K., Felling J., Kronaus H., RéjouMéchain M., Chave J., Reiter K. 2016a. High-resolution forest mapping for behavioural studies in the Nature Reserve "Les Nouragues", French Guiana. Journal of maps 12:26-32. DOI: http://dx.doi.org/10.1080/17445647.2014.972995

Ringler E., Mangione R., Ringler M. 2014. Where have all the tadpoles gone? Individual genetic tracking of amphibian larvae until adulthood. Molecular ecology resources 15:737-746. DOI: $10.1111 / 1755-0998.12345$

Ringler E., Pašukonis A., Fitch WT., Huber L., Hödl W., Ringler M. 2015. Flexible compensation of uniparental care: female poison frogs take over when males disappear. Behavioral Ecology 26:1219-1225. DOI: https://doi.org/10.1093/beheco/arv069

Ringler E., Pašukonis A., Hödl W., Ringler M. 2013. Tadpole transport logistics in a Neotropical poison frog: indications for strategic planning and adaptive plasticity in anuran parental care. Frontiers in Zoology 10:67. DOI: 10.1186/1742-9994-10-67

Ringler E., Pašukonis A., Ringler M., Huber L. 2016b. Sex-specific offspring discrimination reflects respective risks and costs of misdirected care in a poison frog. Animal Behaviour 114:173-179

Ringler E., Ringler M., Jehle R., Hödl W. 2012. The female perspective of mating in $A$. femoralis, a territorial frog with paternal care-a spatial and genetic analysis. PLoS One 7:e40237. DOI: https://doi.org/10.1371/journal.pone.0040237

Ringler M., Ursprung E., Hödl W. 2009. Site fidelity and patterns of short- and long-term movement in the brilliant-thighed poison frog Allobates femoralis (Aromobatidae). 
713 Roithmair ME. 1992. Territoriality and Male Mating Success in the Dart-poison Frog,

714 Epipedobates femoralis (Dendrobatidae, Anura). Ethology 92:331-343. DOI:

715 10.1111/j.1439-0310.1992.tb00970.x

716

717

718

719

720

721

722

723

724

725

726

727

728

729

730

731

732

733

734

Rojas B. 2015. Mind the gap: treefalls as drivers of parental trade-offs. Ecology and evolution 5:4028-4036

Roland AB., O'Connell LA. 2015. Poison frogs as a model system for studying the neurobiology of parental care. Current Opinion in Behavioral Sciences 6:76-81

Roshier DA., Doerr VAJ., Doerr ED. 2008. Animal movement in dynamic landscapes: interaction between behavioural strategies and resource distributions. Oecologia 156:465477. DOI: $10.1007 / \mathrm{s} 00442-008-0987-0$

Rowley JJL., Alford RA. 2007. Techniques for tracking amphibians: the effects of tag attachment, and harmonic direction finding versus radio telemetry. Amphibia-Reptilia 28:367-376. DOI: 10.1163/156853807781374755

Schulte LM., Lötters S. 2014. A danger foreseen is a danger avoided: how chemical cues of different tadpoles influence parental decisions of a Neotropical poison frog. Animal cognition 17:267-275

Schulte LM., Summers K. 2017. Searching for hormonal facilitators: Are vasotocin and mesotocin involved in parental care behaviors in poison frogs? Physiology \& Behavior $174: 74-82$

Schulte LM., Yeager J., Schulte R., Veith M., Werner P., Beck LA., Lötters S. 2011. The smell of success: choice of larval rearing sites by means of chemical cues in a Peruvian poison frog. Animal Behaviour 81:1147-1154 
735 Smith JM., Buchanan J., Downie JR., Riehle MO. 2006. Larval transport does not affect

736 locomotor performance in the stream frog, Mannophryne trinitatis. The Herpetological

$737 \quad$ Journal $16: 333-336$

738 Stamps J. 1995. Motor learning and the value of familiar space. The American Naturalist

$739 \quad 146: 41-58$

740 Stynoski JL. 2009. Discrimination of offspring by indirect recognition in an egg-feeding

741 dendrobatid frog, Oophaga pumilio. Animal Behaviour 78:1351-1356

742 Summers K. 1989. Sexual selection and intra-femalecompetition in the green poison-dart frog, 743 Dendrobates auratus. Animal Behaviour 37:797-805

744 Summers K. 1990. Paternal care and the cost of polygyny in the green dart-poison frog.

745 Behavioral Ecology and Sociobiology 27:307-313

746 Summers K. 1992. Mating strategies in two species of dart-poison frogs: a comparative study.

$747 \quad$ Animal Behaviour 43:907-919

748 Summers K., Tumulty J. 2013. Parental care, sexual selection, and mating systems in neotropical

749 poison frogs. Sexual selection: perspectives and models from the Neotropics. Elsevier

$750 \quad$ Academic Press, New York:289-320

751 Team RDC. 2014. R: A language and environment for statistical computing 3.2.0,

752 http://www.r-project.org

753 Thiele J., Winter Y. 2005. Hierarchical strategy for relocating food targets in flower bats: spatial

754 memory versus cue-directed search. Animal behaviour 69:315-327

755 Thomas RJ., Cuthill IC., Goldsmith AR., Cosgrove DF., Lidgate HC., Proctor SLB. 2003. The

756 trade-off between singing and mass gain in a daytime-singing bird, the European robin.

757 Behaviour 140:387-404 
758 Townsend DS. 1986. The costs of male parental care and its evolution in a neotropical frog.

759 Behavioral Ecology and Sociobiology 19:187-195

760 Ursprung E., Ringler M., Jehle R., Hoedl W. 2011. Strong male/male competition allows for 761 nonchoosy females: high levels of polygynandry in a territorial frog with paternal care.

$762 \quad$ Molecular Ecology 20:1759-1771

763 Wells KD. 1980. Behavoral ecology and social organization of a dendrobatid frog (Colostethus 764 inguinalis). Behavioral Ecology and Sociobiology 6:199-209

765 Wells KD. 2007. The ecology and behavior of amphibians. University of Chicago Press

766 Werner P., Elle O., Schulte LM., Lötters S. 2010. Home range behaviour in male and female

767 poison frogs in Amazonian Peru (Dendrobatidae: Ranitomeya reticulata). Journal of

$768 \quad$ Natural History 45:15-27

769 Weygoldt P. 1987. Evolution of parental care in dart poison frogs (Amphibia: Anura:

770 Dendrobatidae). Journal of Zoological Systematics and Evolutionary Research 25:51-67

771 Wolf LL., Hainsworth FR., Gill FB. 1975. Foraging Efficiencies and Time Budgets in

$772 \quad$ Nectar-Feeding Birds. Ecology 56:117-128

773 Ydenberg RC., Krebs JR. 1987. The tradeoff between territorial defense and foraging in the great 774 tit (Parus major). American Zoologist 27:337-346

775

776 


\section{Figure 1}

Map of the study area

Experimental setup and the distribution of male territories in the study area. Red asterisks represent the center of tracked frog territories $(n=16)$ and white asterisks represent the territory centers of other identified males in the area $(n=49)$. Squares represent the crossarray of thirteen artificial tadpole deposition sites, blue squares representing available pools and gray crossed squares the removed deposition sites. Blue circles represent four potential natural pools, which were visited by tadpole carriers during tracking. Contour lines $(1 \mathrm{~m})$ and the Arataye River are drawn in light gray. 


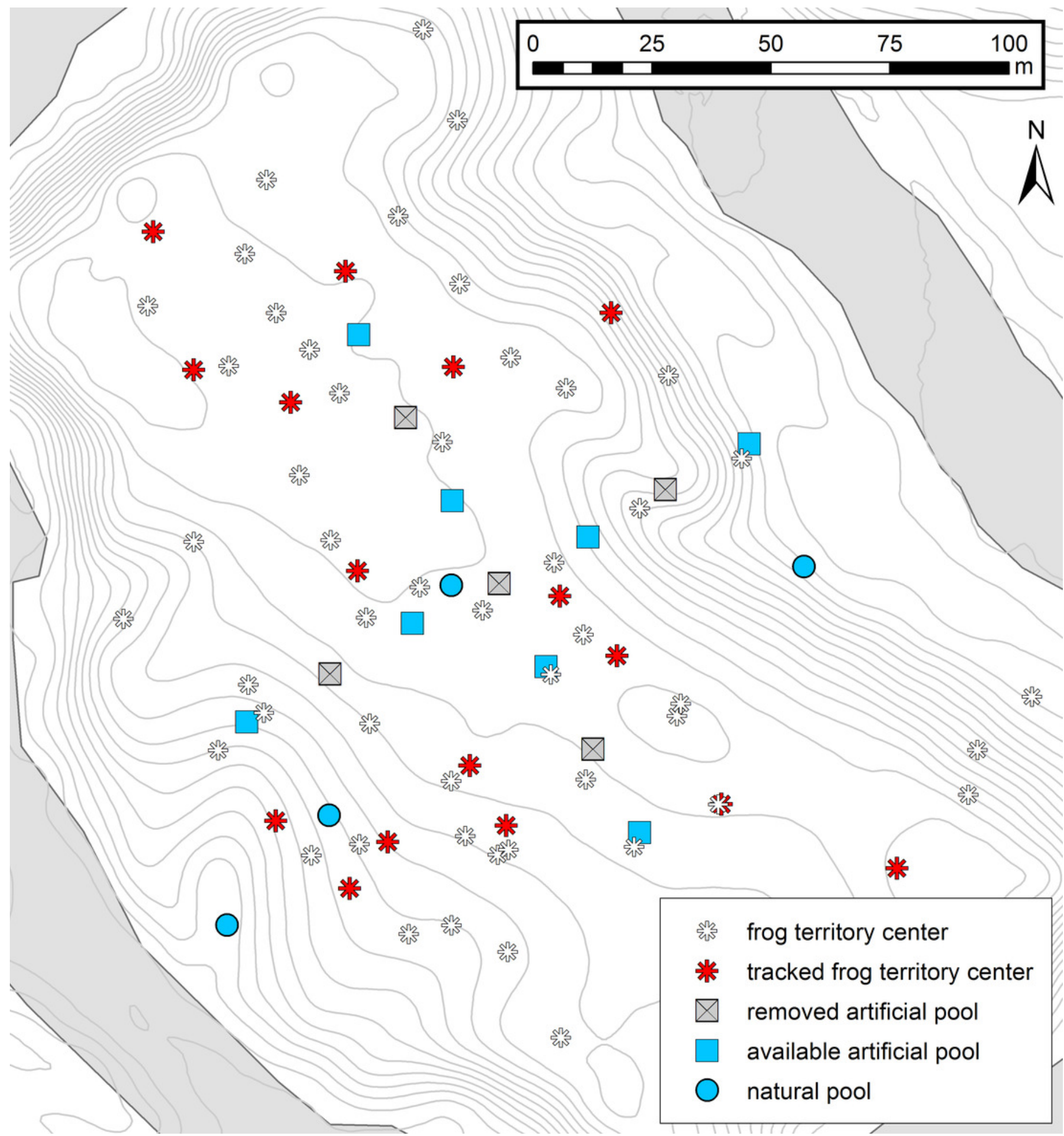




\section{Figure 2}

Tadpole transport trajectories

Trajectory map showing movement patterns of tadpole transporting males to and between the deposition sites. Different colors represent different tracking events ( $n=15,10$ individuals), full lines represent the frog paths obtained by interpolating the consecutive frog locations and dashed lines the missing path from the territory to the first encounter point. For all other symbols see Fig. 1 . 


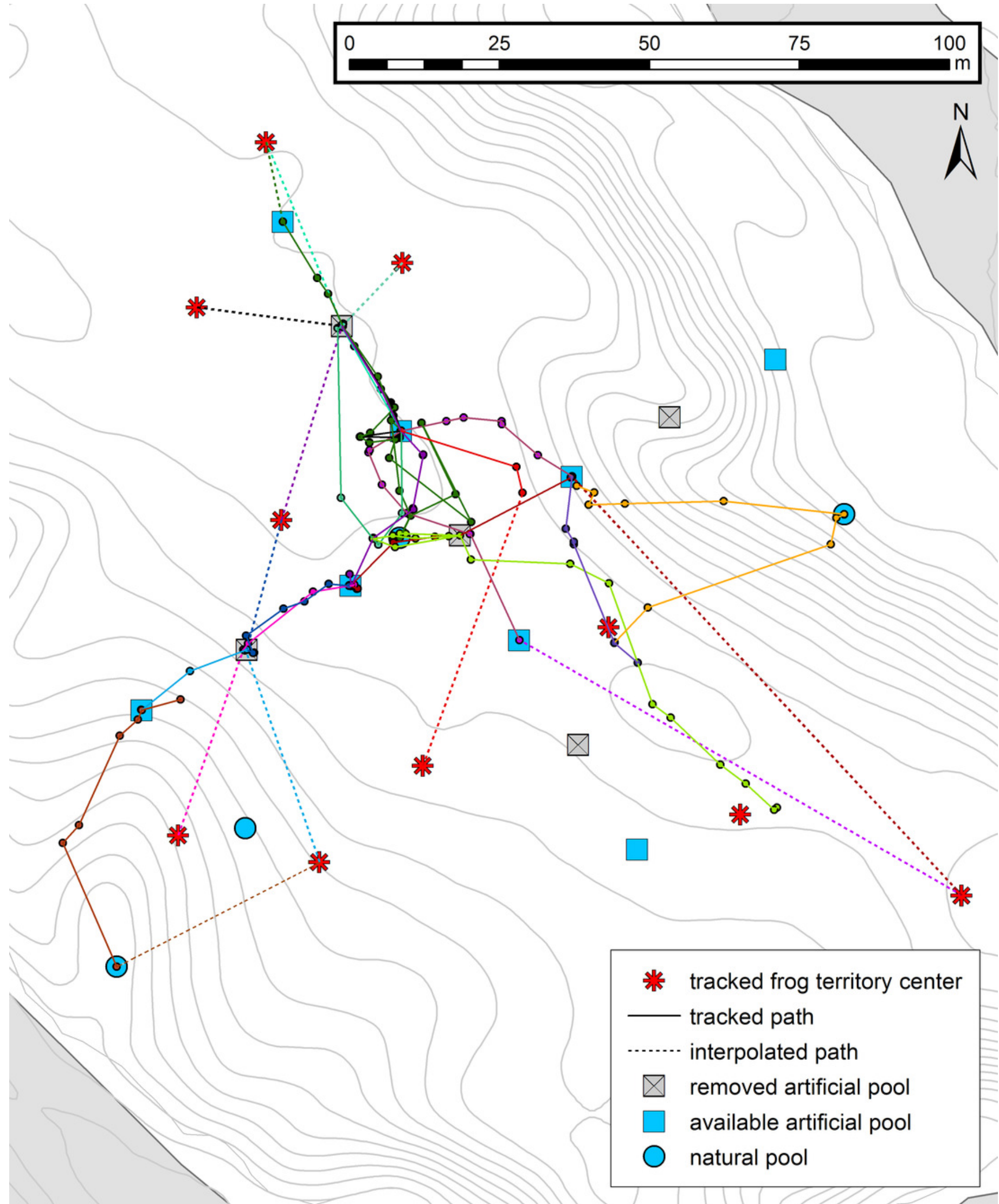


Figure 3

Movement speed during tadpole transport and homing

Boxplot showing the average speed $(\mathrm{m} / \mathrm{h})$ for the TTs and HTs.

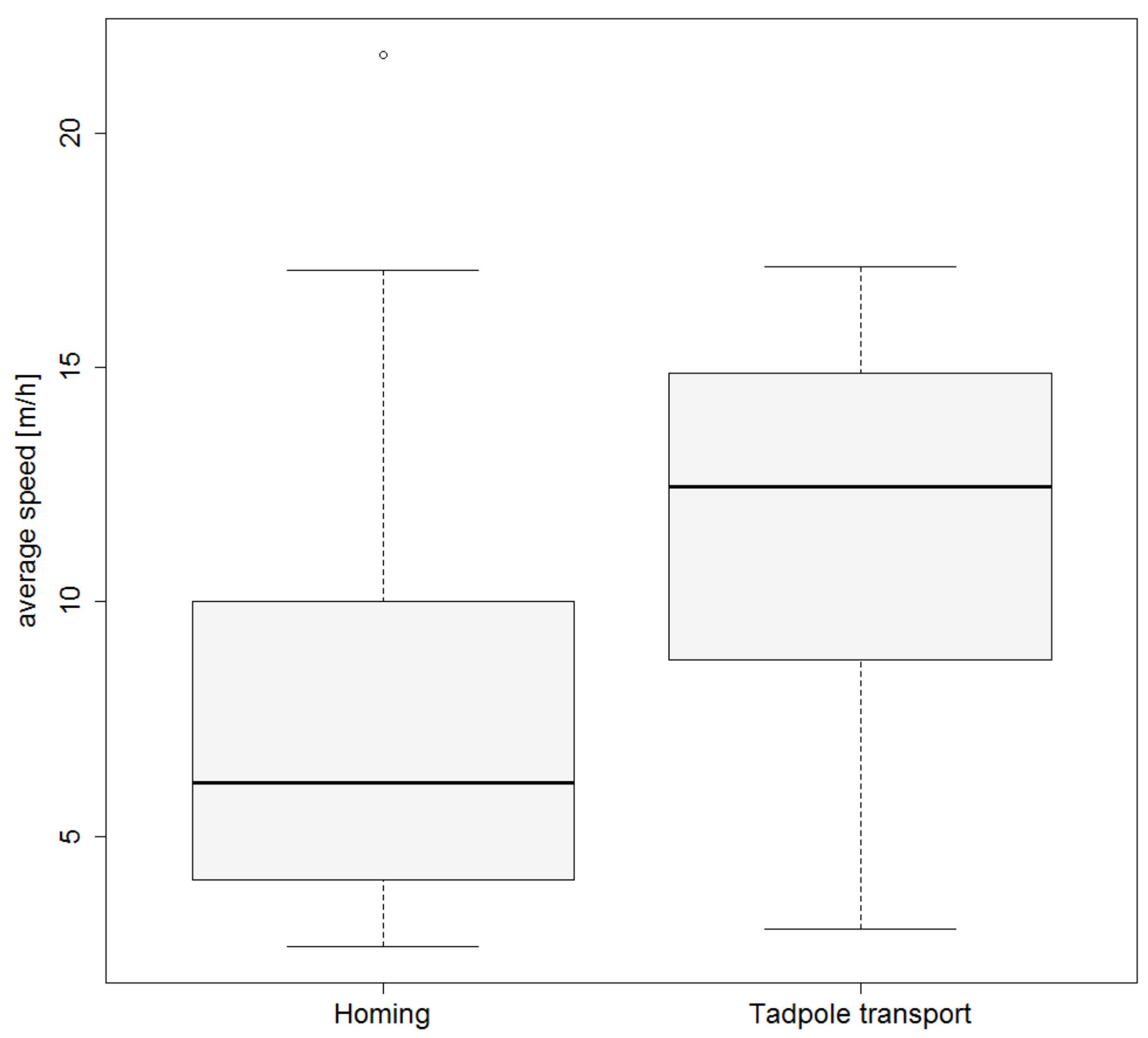




\section{Figure 4}

Tadpole transport and homing trajectories

Part of a polar plot showing A) the tadpole transport (TT) and B) homing (HT) trajectories of male A.femoralis. Each colored line represents one trajectory ( $T: \mathrm{n}=11,7$ individuals; $\mathrm{HT}$ : $n=22,16$ individuals). For better visualization, we only plotted the parts of $T$ s showing the movement between the first two pool sites visited. TTs that did not pass by at least two pool sites are excluded from the plot. All trajectories were normalized to a single starting point (center of the plot), which corresponds to the first pool visited for the TTs and to the last deposition site for the HTs. The full extent of the plot corresponds to $50 \mathrm{~m}$ for $T \mathrm{~s}$ and to 100 $\mathrm{m}$ for HTs. 
A

\section{Tadpole transport}

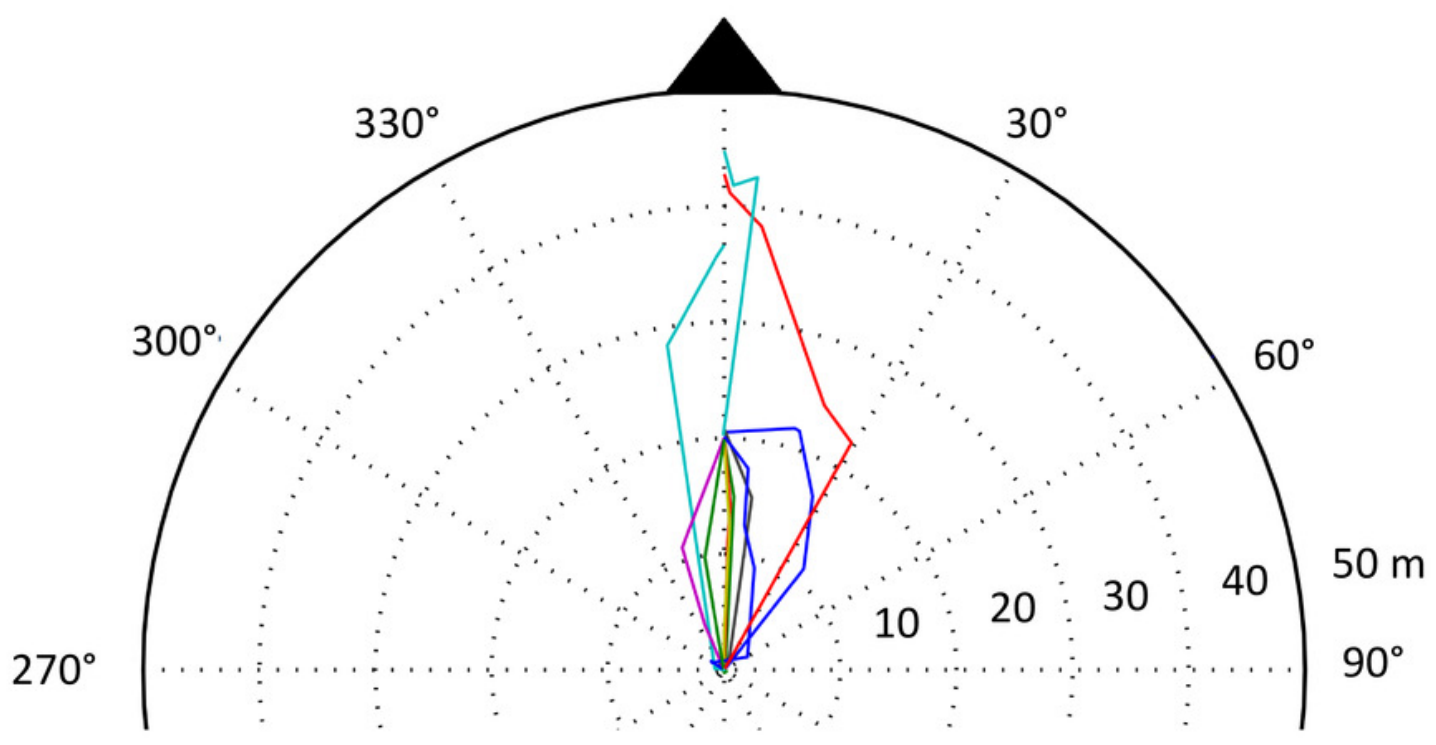

B

Homing

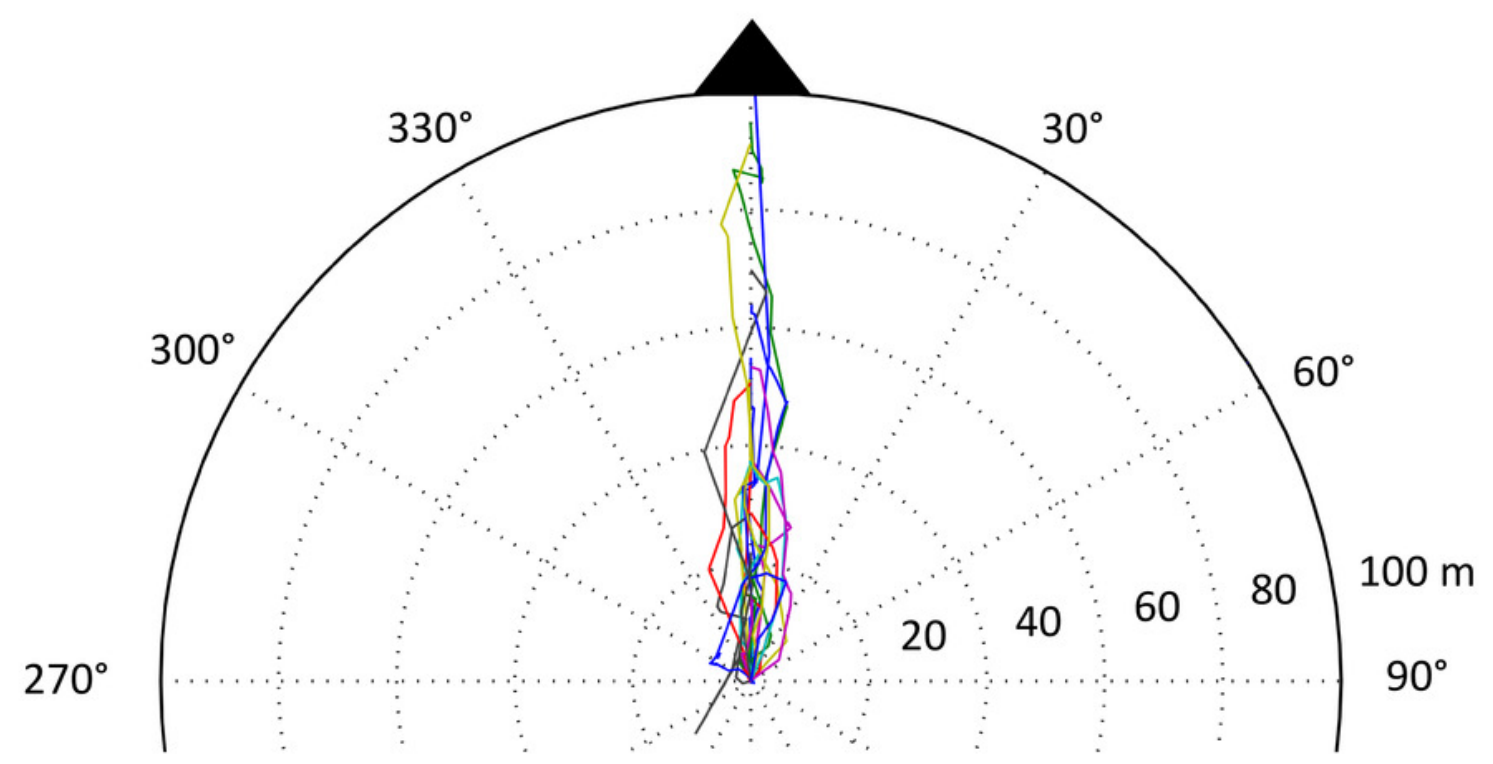

